\title{
Autonomia e coerção na justa medida do tratamento da tuberculose
}

\author{
Autonomy and coercion in the fair measure for tuberculosis treatment \\ Autonomía y coacción en la justa medida para el tratamiento de la tuberculosis
}

Elma Zoboli(a)

Relevante e atual, o artigo de Fortes ${ }^{1}$ aborda implicações éticas do tratamento compulsório da tuberculose, baseando-se em quatro sentidos de justiça, na determinação social e transmissibilidade da doença.

A tuberculose afeta, sobretudo, os mais pobres ${ }^{1}$, pois a saúde-doença é processo histórico-social e não só expressão de características individuais e biológicas ${ }^{2}$. Assim, é preciso ultrapassar os limites dos comportamentos e atitudes individuais na discussão da adesão ao tratamento da tuberculose, pois esta se relaciona com a realidade da pessoa doente, organização do trabalho em saúde, acesso, condições para uma vida digna ${ }^{3}$.

Viver compativelmente com a dignidade humana é a primeira exigência ética da sociedade que se pretende justa. Justiça e felicidade são horizontes da ética a serem conjugados, pois projetos de felicidade excludentes dos mais vulneráveis são desumanos, e exigências de justiça que desconsideram vida em plenitude são pouco vigorosas ${ }^{4}$. Num dos sentidos de justiça, Fortes ${ }^{1}$ referencia o alto grau de coesão dos membros da sociedade para se produzir igualdade de oportunidades para todos. A felicidade implica o florescimento das melhores potencialidades e capacidades individuais; a justiça significa igual oportunidade para todos terem tal florescer ${ }^{4}$. Oportunidade, provavelmente, negada às pessoas com tuberculose, que acabam culpabilizadas por adoecer, enquanto a sociedade, que não garantiu uns mínimos de justiça para assegurar vida digna a todos, segue impune. Fortes ${ }^{1}$ questiona se o doente poderia exigir reparação pela negligência do Estado que não assegurou igual distribuição de bens básicos e oportunidades, gerando iniquidades que vulneram alguns grupos sociais.

A ética aponta para a vida feliz desenvolvida no bojo das exigências da justiça, abrindo caminho à esperança. Quem completou com sucesso o tratamento para tuberculose multirresistente indicou o desejo de viver como decisivo na adesão 5 . O que é isso senão esperança? E como tê-la sem justiça social? É preciso o mútuo reconhecimento da dignidade para ponderar o suficiente, o necessário e a vida de qualidade no âmago do justo ${ }^{4}$.

O mútuo reconhecimento gera vínculo, fundamento da prática de saúde no SUS ${ }^{1}$. Entretanto, se compreender a adesão ao tratamento como decisão autônoma da pessoa com tuberculose pode levar à culpabilização desta, deslocar o fiel da balança para o vínculo, desconsiderando as condições de trabalho e

\footnotetext{
(a) Escola de Enfermagem, Universidade de São Paulo. São Paulo, SP, Brasil.elma@usp.br
} 
organização dos serviços de saúde pode transferir a culpa para os profissionais. Isso remete à justiça como mérito e recompensa ${ }^{1}$, provocando a reflexão: estaria esta ideia de justiça ancorando as premiações às equipes de atenção primária com bons resultados no controle da TB? Não seria culpabilizar os profissionais: se aquela equipe trabalha na mesma rede e consegue bons resultados, por que não conseguimos? É preciso ampliar a compreensão da adesão ao tratamento da tuberculose para discutir, de forma mais justa, menos culpabilizadora, a questão da internação compulsória. Para Fortes ${ }^{1}$, sem ações concretas nos serviços de saúde para criar verdadeiros ambientes de troca, dificulta-se criar, manter, fortalecer vínculos. A boa intenção da equipe para bem cuidar se tornará razão, ganhará peso de argumentação somente ao encontrar eco na estrutura das organizações. Os projetos de felicidade das equipes precisam ser desenvolvidos no bojo de projetos de justiça para a organização do trabalho em saúde. O "êthos burocrático", da justiça, precisa compaginar-se com o "êthos profissional", da excelência (p. 139).

O linguajar pode expressar juízos valorativos, com culpabilização e acusação moral. Fortes ${ }^{1}$ exemplifica que "abandono", um dos desfechos do Programa de $\mathrm{TB}$, traz a ideia de que o doente não foi capaz de motivar-se para o tratamento e a equipe incapaz de esclarecê-lo. Isso gera questões éticas na Atenção Básica: como informar os usuários para conseguir a adesão ao tratamento? ${ }^{6}$. O profissional, sentindo-se incapaz de cumprir seus deveres, sofre moralmente. Mantém-se o usuário como alguém incapaz, necessitado da condução dos profissionais por ações paternalistas, autoritárias, que acabam justificando o tratamento compulsório. A abordagem ética continua restrita às responsabilidades individuais, e a da tuberculose segue, predominantemente, restrita a tratamentos medicamentosos, intervenções na cadeia de transmissão, diagnóstico precoce.

Fortes ${ }^{1}$ destaca "pacientes recalcitrantes", que se soma a: faltante, suspeito, combate, controle. Todos implicitamente coercitivos e mantenedores da submissão dos usuários ${ }^{7}$, com abordagem paternalista, autoritária, utilitarista da saúde pública, em nome do benefício coletivo. Suspeito é pessoa presumivelmente culpada de crime ou ofensa, que, certamente, não é a condição de quem apresenta sintomas e sinais de tuberculose ${ }^{7}$. Mas, suspeitos e comunicantes são 'investigados'. Estes termos reiteram o estigma relativo à tuberculose; implicam a criminalização dos mais vulneráveis ${ }^{7}$, passível de punição com tratamento compulsório, pena de segunda instância para quem descumpre a emanada na primeira. Controle designa poder para dominar, regular, restringir uma atividade ou processo; poder de influência e autoridade sobre um comportamento 7 . Seu uso tem implicações éticas, pois coloca os profissionais na condição de comando, de sabedores do necessário para o paciente resolver seus problemas de saúde ${ }^{7}$, definidos, também, pela equipe. Comunidade e pacientes não são considerados interlocutores válidos, distanciando-se o reconhecimento mútuo de dignidade. Os profissionais, assim, acreditam ter poder sobre o paciente e sua vida, infringindo direitos, desrespeitando a autonomia, justificando ações coercitivas para regular o comportamento ${ }^{7}$.

A questão da tuberculose ultrapassa a competência técnica dos serviços e equipes; é fundamental a ética, como dignidade, justiça social e acolhimento7. Concordando com Fortes ${ }^{1}$, urge trabalhar na reconstrução da dimensão pública, coletiva da questão da tuberculose, com vistas à justa medida no acompanhamento das pessoas que sofrem com a doença e para debelar as condições sociais injustas que a determinam, ceifando sonhos e possibilidades de muitos brasileiros. 


\section{Referências}

1. Fortes PD. A justa dose da medida: o tratamento compulsório da tuberculose em questão. Interface. 2016; 20(58):773-81.

2. Buss PM, Pellegrini-Filho A. A saúde e seus determinantes sociais. Physis. 2007; 17(1):77-93.

3. Bertolozzi MR. Adesão ao tratamento da tuberculose na perspectiva da estratégia do tratamento diretamente observado ("DOTS") no município de São Paulo (tese). São Paulo (SP): Escola de Enfermagem, Universidade de São Paulo; 2005.

4. Cortina A. ¿Para qué sirve realmente la ética? Madrid: Paidós; 2013.

5. Ferreira KR. A adesão ao tratamento no caso da tuberculose multirresistente (tese). São Paulo (SP): Escola de Enfermagem, Universidade de São Paulo; 2014.

6. Zoboli ELCP. Bioética e atenção básica: um estudo de ética descritiva com enfermeiros e médicos do Programa Saúde da Família, São Paulo (tese). São Paulo (SP): Faculdade de Saúde Pública, Universidade de São Paulo; 2003.

7. Zachariah $R$, Harries AD, Srinath $S$, Ram S, Viney K, Singogo $E$, et al. Language in tuberculosis services: can we change to patient-centred terminology and stop the paradigm of blaming the patients? Int J Tuberc Lung Dis. 2012; 16(6):714-7. 